\title{
Risk faktörlerinin arteriovenöz fistüllerde anevrizma oluşumu üzerine etkisinin değerlendirilmesinde yeni bir yaklaşım: Karar ağacı metodu
}

\section{A new approach to the evaluation of the effect of risk factors on the development of aneurysm in arteriovenous fistulas: The decision tree method}

\author{
Emre KARAKAYA ${ }^{*} \square$, Aydıncan AKDURํㅁ, Sait Can YÜCEBAŞ² $\square$, Deniz Sarp BEYAZPINAR³ $\square$
}

1'Başkent Üniversitesi, Genel Cerrahi Anabilim Dalı, Ankara,/TÜRKIYE

Çanakkale Onsekiz Mart Üniversitesi, Mühendislik Fakültesi, Bilgisayar Mühendisliği Departmanı, Çanakkale/TÜRKIYE 33aşkent Üniversitesi, Kalp Damar Cerrahisi Anabilim Dalı, Ankara,/TÜRKIYE

\section{öz}

Amaç: Vasküler anevrizmalar; arteriyovenöz fistüllerde geç dönemde görülen ve hayatı tehdit eden bir komplikasyondur. Bizim bu çalışmadaki amacımız arteriyovenöz fistüllerde anevrizma gelişimine neden olan risk faktörlerini karar ağacı yöntemi ile değerlendirerek risk algoritması oluşturmaktır.

Gereç ve Yöntemler: Merkezimizde 2016-2020 yılları arasında arteriyovenöz fistül ameliyatı yapılan 520 hastanın demografik verileri, ek hastalıkları (diabetes mellitus, koroner arter hastalığı, hipertansiyon, kalp yetmezliği) ve anevrizma durumları retrospektif olarak belirlendi. Anevrizma oluşumu üzerindeki risk faktörleri karar ağacı metodu ile incelendi.

Bulgular: Hastaların 68 (\%13) tanesinde anevrizma geliştiği tespit edildi. Oluşturulan algoritmada anevrizma gelişiminde en önemli risk faktörü arteriyovenöz fistülün lokalizasyonu iken kalp yetmezliğinin anevrizma gelişimi açısından bir etkisi olmadığı görüldü.

Sonuçlar: Oluşturduğumuz algoritmaya göre hastanın değerlendirilmesi, yapılacak arteriyovenöz fistül ameliyatlarında anevrizma gelişim riskini doğru bir şekilde belirleyebilir ve bu riski en aza indirgeyebilir.

Anahtar kelimeler: Arteriyovenöz fistül; anevrizma; böbrek yetmezliği 


\section{ABSTRACT}

Aim: Vascular aneurysms; It is a life-threatening complication of arteriovenous fistulas seen in the late period. Our aim in this study is to create a risk algorithm by evaluating the risk factors that cause aneurysm development in arteriovenous fistulas with the decision tree method.

Material and Methods: Demographic data, comorbidities (diabetes mellitus, coronary artery disease, hypertension, heart failure) and aneurysm status of 520 patients who underwent arteriovenous fistula surgery in our center between 2016-2020 were determined retrospectively. Evaluation of risk factors affecting aneurysm formation was done by decision tree method.

Results: Aneurysm was detected in 68 (13\%) of the patients. In the created algorithm, the most important risk factor in the development of aneurysm was the location of the arteriovenous fistula, while heart failure had no effect on the development of aneurysm.

Conclusion: Evaluation of the patient according to the algorithm we created can accurately determine the risk of aneurysm development in arteriovenous fistula surgeries and can minimize this risk.

Keywords: Arteriovenous fistula; aneurysm; kidney failure

\section{Giriş}

Son dönem böbrek yetmezliği (SDBY) olan hastalarda hemodiyaliz amacı ile vasküler erişimde arteriovenöz fistül (AVF) kullanımı, enfeksiyon gelişimi, kardiyovasküler komplikasyonlar ve ölüm oranları açısından değerlendirildiğinde santral venöz kateter (SVK) kullanımına göre altın standarttır [1]. Türk Nefroloji Derneği'nin 2019 verilerine göre ülkemizde hemodiyaliz tedavisi alan 61341 hastanın $46929(\% 76,51)$ tanesinde vasküler erişim arterivenöz fistüller yoluyla sağlanmaktadır [2].

Komplikasyonlar açısından değerlendirildiğinde SDBY hastaIarının hastane yatışlarının \%15'i AVF komplikasyonları nedeni ile olduğu görülmektedir [3]. Ayrıca Amerika Birleşik Devletleri verilerine göre SDBY hastalarına yapılan harcamaların \%14-17'sinin AVF komplikasyonlarının tedavisinde kullanıldığı belirlenmiştir [4]. AVF komplikasyonları genel olarak; kanama, tromboz, venöz hipertansiyon, anevrizma, steal sendromu, stenoz ve kalp yetmezliği olarak sıralanır [5]. Anevrizma AVF hastalarının \%2-10'unda görülen geç dönem komplikasyondur [6]. Ani rüptür ve kanama ihtimali olması nedeni ile hayati tehdit oluşturan bir komplikasyondur (Şekil 1). Komplikasyonların oluşumunda rol alan risk faktörlerine baktığımızda açılan AVF'nin lokalizasyonu, ileri yaş, kadın cinsiyet, hipertansiyon ve kalp damar hastalıkları ön plana çıkmaktadır [3, 7].

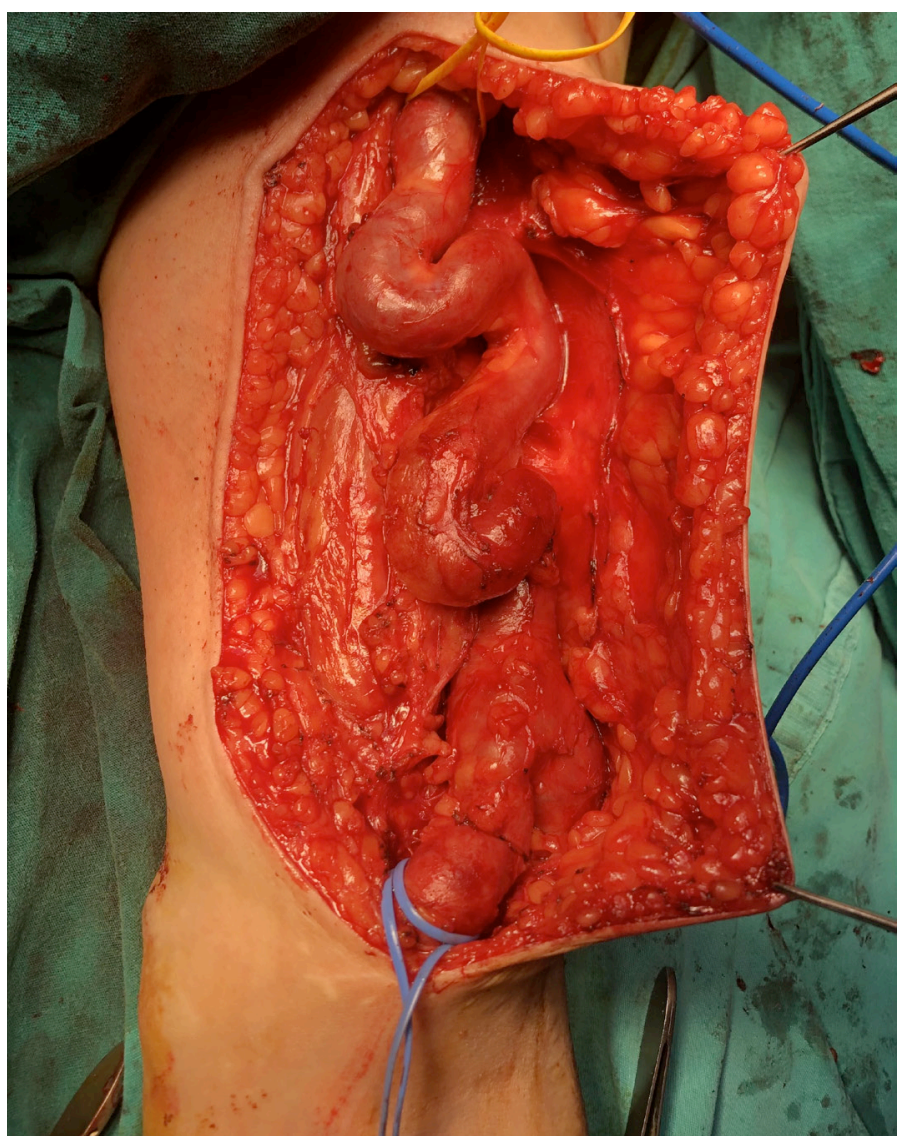

Şekil 1: Brakiosefalik arteriovenöz fistülü olan hastada anevrizma gelişmiş sefalik ven. (Dr. Emre KARAKAYA arşivinden) 
Karar ağacı metodu makine öğrenmesinin tıp alanındaki uygulamalarında sıklıkla tercih edilen bir yöntemdir. Bu yöntemde hastalığa etki eden eldeki faktörler ilgili modele verilir. Model çeşitli matematik ve istatistik hesaplar kullanarak incelenen duruma etki eden faktörleri ve bu faktörlerin birbirleri ile ilişkilerini görsel şekilde bir ağaç yapısı üzerinde sunar. Ağaç yapısı üzerindeki dallar takip edilerek bu faktörlerin sonuca etkisi kurallı bir algoritma şeklinde çıkarılır $[8,9]$.

Bizim bu çalışmamızdaki amacımız karar ağacı metodunu kullanarak AVF'si olan hastalarda anevrizma gelişimine neden olan risk faktörlerinin önem sırasını ve birbiri ile olan ilişkisini belirleyen bir algoritma oluşturmaktır. Bu algoritma sayesinde AVF ameliyatı planlanan hastalarda anevrizma gelişimi ile buna bağlı morbidite ve mortalite riski en aza indirilebilir.

\section{Gereç ve Yöntemler}

Çalışmamız için Başkent Üniversitesi Klinik Araştırmalar Etik Kurulundan KA21/316 numarası ile onay alınmıştır.

Çalışmamızda Başkent Üniversitesi Ankara Hastanesi'nde Ocak 2016 ile Ocak 2021 tarihleri arasında AVF ameliyatı olmuş toplam 544 hasta hastane otomasyon sistemi aracılığı ile retrospektif olarak incelendi. İlk ameliyatında greft kullanılan ve intraoperatif olarak arteriovenöz anastomoz bölgesinde akım sağlanamayan hastalar ile ameliyat sonrası kontrolleri için başvurmayan hastalar çalışma dışı bırakıldı. Toplamda 520 hasta çalışmaya dahil edildi. Hastaların yaşları, cinsiyetleri, AVF lokalizasyonları, anevrizma gelişip gelişmediği ve komplikasyon gelişimi açısından risk teşkil eden ek hastalıkları (diabetes mellitus (DM), hipertansiyon (HT), kalp yetmezliği (KY), koroner arter hastalığı (KAH)) belirlenerek kayıt altına alındı.

Bu veri kümesi karar ağacı modelinin oluşturulması için kullanıldı. Bu yöntemde ağacın her bir düğümü için eldeki parametrelerin her biri öz-yineli olacak şekilde bilgi kazancı oranı kullanılarak test edildi. İlgili oranın hesaplanması için her bir parametreye ait bölünmeden önceki ve sonraki entropi hesaplandı [8, 10].

İlgili hesaplamalar için Eşitlik-1'den eşitlik-+'e kadar olan formüller kullanıldı. Buna göre Si bir Ci sınıfındaki örnekleri, Pi ise I verisinin Ci sınıfına ait olma olasılığını gösterirken, $A=\{a 1$, a2, ..., av\} kümesindeki bir parametre için gerekli bilgi Eşitlik-1 () formülüne göre hesaplandı. Burada seçilen bir A parametresi için örnek uzayını v adet alt kümeye bölmek için gerekli entropi Eşitlik-2 ( )'deki gibi hesaplandı. Bir Ci sınıfına ait Sj altkümesindeki örnekler Sij ile gösterildiğinde bu altküme için gerekli bilgi Eşitlik-3 ('deki gibi hesaplandı. Bu hesaplamalar sonunda eldeki sınıf bilgisine göre herhangi bir parametreye ait bilgi kazancı Eşitlik-4 ('deki şekliyle hesaplandı. İlgili ağacın oluşturulması için eldeki nümerik değerlerden dolayı C4.5 algoritması kullanıldı. Oluşturulan modelin geçerlilik testi için 10 katmanlı çapraz geçerlilik testi kullanıldı [11]. Oluşturulan ağacın en son dallarındaki 'düşük risk' ya da 'yüksek risk' tanımlamaları aynı gruptaki diğer hastalara olan oranına göre yapıldı.

\section{Bulgular}

Çalışmamıza toplamda 520 hasta dahil edildi. Bu hastaların $317(\% 60,9)$ tanesi erkekti. Hastaların yaş ortalaması 55,2 (9-89) idi. Hastaların 203 (\%39) tanesinde brakiosefalik (BS), $179(\% 34,4)$ tanesinde radiosefalik (RS), $86(\% 16,5)$ tanesinde brakiobazilik (BB), $39(\% 7,5)$ tanesinde radiosefalik snuff-box (SB), 12 (\%2,3) tanesinde femorofemoral (FF) arteriovenöz fistül ameliyatı gerçekleştirildi. AVF ameliyatı yapılan hastaların toplamda 68 (\%13) tanesinde anevrizma geliştiği tespit edildi. Anevrizma gelişen AVF'lerin 41 tanesi BS, 14 tanesi RS, 11 tanesi BB, 1 tanesi SB ve 1 tanesi FF lokalizasyonlu idi.

Ek hastalıklar açısından hastalar incelendiğinde; hastaların 368 (\%70,8) tanesinde HT, 151 (\%29) tanesinde DM, 125 (\%24) tanesinde KAH ve $51(\% 9,8)$ tanesinde KY tespit edildi (Tablo 1).

\begin{tabular}{|c|c|c|c|}
\hline \multicolumn{4}{|c|}{$\begin{array}{l}\text { Tablo 1: Hastaların demografik bilgileri, ek hastalıkları ve } \\
\text { arteriovenöz fistül türlerinin dağılımı }\end{array}$} \\
\hline $\begin{array}{l}\text { Demografik } \\
\text { bilgiler }\end{array}$ & & AVF türü & n (\%) \\
\hline Yaş (min-maks) & $55.2(9-89)$ & Brakiosefalik & $203(\% 39)$ \\
\hline Cinsiyet (E/K) & $317 / 203$ & Radiosefalik & $179(\% 34,4)$ \\
\hline Ek hastalık & $\mathrm{n}(\%)$ & Brakiobazilik & $86(\% 16,5)$ \\
\hline Hipertansiyon & $368(\% 70,8)$ & Snuff-box & $39(\% 7,5)$ \\
\hline Diabetes Mellitus & $151(\% 29)$ & Femorofemoral & $12(\% 12,3)$ \\
\hline $\begin{array}{l}\text { Koroner arter } \\
\text { hastalığı }\end{array}$ & 125 (\%24) & Toplam & $520(\% 100)$ \\
\hline Kalp yetmezliği & $51(\% 9,8)$ & & \\
\hline \multicolumn{4}{|c|}{ Kısaltmalar: min: minimum; maks: maksimum; E: erkek; K: kadın } \\
\hline
\end{tabular}

Karar ağacı yöntemine göre yapılan algoritmamızda arteriovenöz fistül ameliyatı sonrası anevrizma gelişiminde en fazla rol oynayan faktör fistül lokalizasyonudur. SB fistüllerin \%97'sinde, FF fistüllerin ise \%92'sinde anevrizma görülmediğinden dolayı anevrizma gelişme riski düşüktür. $\mathrm{RS}, \mathrm{BS}$ ve $\mathrm{BB}$ fistüllerinde ise anevrizma gelişimi diğer risk faktörlerine bağlıdır (Şekil 2).

Brakiosefalik arteriovenöz fistül açılan hastalarda anevrizma gelişimine etki eden en önemli faktör DM'dir. DM'si olan hasta- 


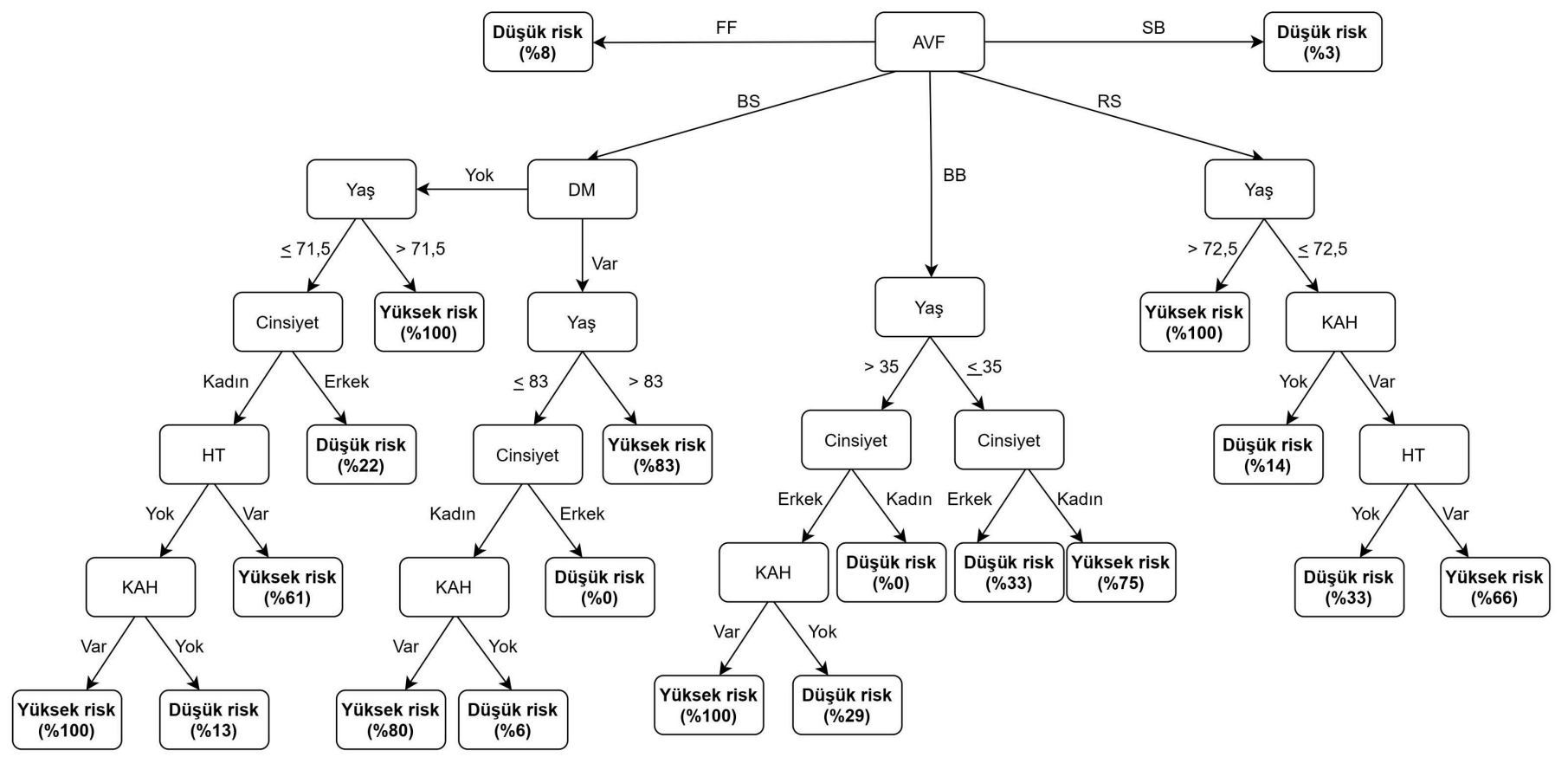

Şekil 2: Karar ağacı yöntemi ile oluşturulan anevrizmalarda risk faktörlerinin etki algoritması. (AVF: arteriyovenöz fistül; FF: femorofemoral arteriyovenöz fistül; SB: snuff-box arteriyovenöz fistül; BS: brakiosefalik arteriyovenöz fistül; BB: brakiobazilik arteriyovenöz fistül; RS: radiosefalik arteriyovenöz fistül; DM: diabetes mellitus; $\mathrm{KAH}$ : koroner arter hastalığı; HT: hipertansiyon)

ların anevrizma gelişim riskini değerlendirmek için yaşa bakılır. Yaşı 83'ten büyük olan hastalar anevrizma gelişimi için yüksek riskli hastalardır. Yaşı 83 ve altında olan hastalarda da cinsiyet değerlendirmesi yapılır. Erkek cinsiyet anevrizma gelişimi için düşük risk taşırken kadın hastalar $\mathrm{KAH}$ eşlik ediyorsa yüksek riskli, etmiyorsa düşük risklidir. DM'si olmayan hastalarda ise anevrizma gelişim riski için yaş açısından eşik değer 71,5'tur. Yetmiş bir yaşından büyük hastalar anevrizma gelişimi için yüksek risk taşırken, 71 yaş ve altında olan hastalarda cinsiyet değerlendirmesi yapılır. Erkek cinsiyetli hastalar düşük riskli iken kadın cinsiyetli ve HT'si olan hastalar anevrizma gelişimi için yüksek risklidir. Bu gruptaki kadın hastalarda ek hastalık olarak HT yerine $\mathrm{KAH}$ mevcut ise bu durum anevrizma gelişimi açısından yüksek risk teşkil eder.

Brakiobazilik arteriovenöz fistülü olan hastalarda ise anevrizma gelişimi açısından en önemli risk faktörü yaştır. Yaşı 35 ve altında kadın hastalar anevrizma gelişimi açısından erkeklere göre çok yüksek bir fark olmasa da daha fazla risk taşır. Otuz beş yaşın üzerindeki erkek hastalarda $\mathrm{KAH}^{\prime} ı$ olan erkek hastalar yüksek riskli iken, kadın hastalar ve KAH'ı olmayan erkek hastalar düşük risklidir.

Radiosefalik arteriovenöz fistülü olan hastalarda hastalarda anevrizma gelişimini belirleyen risk faktörü yaş olup eşik değeri 72,5'tur. Yaşı 72,5'tan yüksek hastalar anevrizma gelişimi açısından yüksek riskli gruptadır. Yaşı 72,5 ve altında olan hastalarda $\mathrm{KAH}$ olup olmadığı sorgulanır. KAH olan HT eşlik ediyor ise bu hastalar anevrizma gelişimi açısından yüksek riskli, KAH olmayan ve $\mathrm{KAH}$ varlığına $\mathrm{HT}$ eşlik etmeyen hastalar ise düşük risklidir.

\section{Tartışma}

Yaptığımız çalışma sonucunda AVF'lerde anevrizma gelişimine neden olan risk faktörlerinin önem derecesini ve birbirleri ile olan ilişkisini belirleyen bir algoritma oluşturduk.

Arteriovenöz fistüllerin geç dönem komplikasyonlarından olan anevrizmalar zaman içerisinde diyaliz iğnesinin damar duvarındaki tekrarlayıcı travma etkisine bağlı olarak boyut olarak genişlerler. Anevrizmanın genişlemesi rüptür ve kanama ihtimalini arttırırak hayatı tehdit eden durum oluşturur. Literatürde yapılmış çalışmalarda proksimaldeki AVF'lerde distaldeki AVF'lere nazaran daha çok anevrizma geliştiği bildirilmiştir [6, 12]. Bizim çalışmamızda geliştirdiğimiz algoritmada da literatür ile paralel olarak üst ekstremite AVF'lerde SB fistüller anevrizma gelişimi açısından en düşük riskli fistül grubunu oluşturmaktadır.

Yaş ile AVF bağımlı komplikasyonların arasındaki ilişki incelendiğinde literatürde farklı görüşler yer aldığı görülmektedir. Yapılan çalışmalar incelendiğinde bazı çalışmalar yaşın AVF komplikasyonu üzerine herhangi bir etkisi olmadığını belirtir- 
ken, diğer çalışmalar ise eşik değeri değişken olmakla birlikte ileri yaşın AVF'lerde komplikasyon sıklığında artışa yol açtığını savunmaktadır [3, 13, 14]. Bizim çalışmamız sonucu ortaya çıkan algoritma incelendiğinde çeşitli ek risk faktörlerine bağımlı olarak belirli yaşların üzerinde anevrizmanın daha sık meydana geldiği görülmektedir.

Arteriyövenöz fistüllerde, devamlılığın süresini belirleyen ana faktörlerden bir tanesi anastomoz yapılan veninin çapıdır. Wong ve arkadaşları yaptıkları bir çalışmada doppler ultrasonografi ile damar çaplarını ölçerek fistüllerin çalışma süre ile olan ilişkisini araştırmışlar ve çalışma sonucunda 1,6 mm'den daha küçük çaplı damarlarda anastomoz yapılmaması gerektiğini, ayrıca venin çapının küçüklüğü ile komplikasyon görülme olasılığının doğru orantılı olduğunu belirtmişlerdir [15]. AVF'lerde komplikasyon gelişimine etki eden risk faktörleri araştıııldığında literatürde kadınlarda ven çaplarının daha küçük olması nedeni ile genelde daha çok komplikasyon geliştiği düşünülmektedir $[16,17]$. Bizim algoritmamızda cinsiyetin anevrizma gelişiminde primer olarak etkisi olmamakla birlikte diğer risk faktörleri ile değerlendirildiğinde etkisi olduğu gözlenmektedir. Algoritmamızda genelde kadın cinsiyetin anevrizma gelişimi için risk oluşturduğu gözlenirken sadece BB fistüllerde başka bir ek risk faktörünün olmadığı durumlarda kadın cinsiyetin anevrizma gelişimi üzerine belirgin bir etkisi olmadığını görmekteyiz. Biz bu durumun bazilik venin çapının her iki cinsiyette genelde geniş olmasından ve bu hastalarda HT ya da DM gibi ek hastalıklar olmadığından damar yapısının olumsuz yönde etkilenmemesinden kaynaklandığını düşünmekteyiz.

Koroner arter hastalığı, HT, KY ve DM gibi ek hastalıklar SDBY hastalarında direk olarak kardiyapulmoner kapasiteyi etkileyen hastalıklardır [18]. Ayrıca DM intimada köpük hücreleri birikimine neden olarak damar içinde aterosklerotik lezyonların gelişmesine yol açar. DM vasküler yapılarda güçlü bir fibrojenik uyarı meydana getirerek mikro ve makrovasküler hasarlanma meydana getirir [6]. Literatürde DM'nin AVF'de komplikasyon gelişimine yol açması tartışmalı bir konudur [4, 6]. Salahi ve arkadaşlarının yaptıkları bir çalışmada ile DM'nin anevrizma gelişimi ile herhangi bir ilişkisi gösterilememiştir [6]. Bizim algoritmamızda ise $\mathrm{KAH}, \mathrm{DM}$ ve HT'nin anevrizma gelişimi ile ilişkisi gösterilebilmişken, KY'nin anevrizma gelişimi üzerine herhangi bir etkisi gösterilememiştir.

Çalışmamızın birkaç kısıtlaması mevcuttur. Bunlardan bir tanesi AVF açılan hastalarda damar duvarı yapılarının, vasküler yapıların çaplarının ve anastomoz genişliğinin doppler ultrasonografi gibi yöntemlerle değerlendirilmemesidir. İleride bu konuda yapılacak olan prospekif bir çalışmada bu değerlendirmelerin yapılması daha doğru sonuçların ortaya çıkmasına neden olacaktır. Ayrıca hastaların kardiyopulmoner kapasite ölçümlerinin kantitatif olarak yapılması, bu hastalarda daha ayrıntılı bir şekilde sınıflama yapılmasına imkan verebilir.

\section{Sonuç}

Anevrizma gelişimi AVF'lerin kanama ve perforasyon riski yüksek olan ve hayatı tehdit eden geç dönem komplikasyonlarındandır. AVF ameliyatı yapılması planlanan hastalar karar ağacı metodu ile oluşturduğumuz algoritmaya göre incelendiğinde anevrizma gelişimi açısından daha doğru bir risk tahmini yapılabilir ve uygun hastada uygun lokalizasyondan AVF açılarak bu risk en aza indirgenebilir.

\section{Çıkar çatışması / finansal destek beyanı}

Bu yazıdaki yazarların herhangi bir çıkar çatışması yoktur. Yazının herhangi bir finansal desteği yoktur.

\section{Referanslar}

1. Ravani P, Palmer SC, Oliver MJ et al. Associations between hemodialysis access type and clinical outcomes: a systematic review. J Am Soc Nephrol 2013; 24: 465-73.

2. Ates K, Süleymanlar G, Nurhan S. Türkiye'de Nefroloji, Diyaliz ve Transplantasyon-Registry 2019. TC Sağlık Bakanlığı ve Türk Nefroloji Derneği Ortak Raporu. 2019.

3. Feldman HI, Held PJ, Hutchinson JT, Stoiber E, Hartigan MF, Berlin JA. Hemodialysis vascular access morbidity in the United States. Kidney Int 1993; 43: 1091-6.

4. Astor BC, Coresh J, Powe NR, Eustace JA, Klag MJ. Relation between gender and vascular access complications in hemodialysis patients. Am J Kidney Dis 2000; 36: 1126-34.

5. Belli S, Yabanoglu H, Aydogan C, Parlakgumus A, Yildirim S, Haberal M. Surgical interventions for late complications of arteriovenous fistulas. Int Surg 2014; 99: 467-74.

6. Salahi H, Fazelzadeh A, Mehdizadeh A, Razmkon A, Malek-Hosseini SA. Complications of arteriovenous fistula in dialysis patients. Transplantation proceedings 2006; 38: 1261-4.

7. Hirth RA, Turenne MN, Woods JD et al. Predictors of type of vascular access in hemodialysis patients. JAMA 1996; 276: 1303-8.

8. Quinlan JR. Induction of decision trees. Machine learning 1986; $1: 81-106$

9. Albu A, editor From logical inference to decision trees in medical diagnosis. 2017 E-Health and Bioengineering Conference (EHB); 2017: IEEE. 
10. Shannon $\mathrm{CE}$, Weaver W. The mathematical theory of communication. Urbana: University of Illinois Press 1949; 96.

11. Quinlan JR. Programs for Machine Learning C4. 51993.

12. Letachowicz K, Bardowska K, Krolicki T et al. The impact of location and patency of the arteriovenous fistula on quality of life of kidney transplant recipients. Ren Fail 2021; 43: 113-22.

13. Churchill DN, Taylor DW, Cook RJ et al. Canadian Hemodialysis Morbidity Study. Am J Kidney Dis 1992; 19: 214-34.

14. Rocco MV, Bleyer AJ, Burkart JM. Utilization of inpatient and outpatient resources for the management of hemodialysis access complications. Am J Kidney Dis 1996; 28: 250-6.
15. Wong V, Ward R, Taylor J, Selvakumar S, How TV, Bakran A. Factors associated with early failure of arteriovenous fistulae for haemodialysis access. Eur J Vasc Endovasc Surg 1996; 12: 207-13.

16. Feldman $\mathrm{HI}$, Kobrin S, Wasserstein A. Hemodialysis vascular access morbidity. J Am Soc Nephrol 1996; 7: 523-35.

17. Hussain KM, Kogan A, Estrada AQ, Kostandy G, Foschi A, Dadkhah S. Referral pattern and outcome in men and women undergoing coronary artery bypass surgery--a critical review. Angiology 1998; 49: 243-50.

18. Dobbels F, De Bleser L, De Geest S, Fine RN. Quality of life after kidney transplantation: the bright side of life? Adv Chronic Kidney Dis 2007; 14: 370-8. 